\title{
Multiple Sclerosis Epidemiology in East Asia, South East Asia and South Asia: A Systematic Review
}

\author{
Sharareh Eskandarieh ${ }^{a}$ b Pouria Heydarpour $^{a} \quad$ Alireza Minagar ${ }^{c}$ \\ Shadi Pourmand ${ }^{\mathrm{a}}$ Mohammad Ali Sahraian $^{\mathrm{a}}$ \\ ${ }^{a}$ MS Research Center, Neuroscience Institute, and ${ }^{b}$ Brain and Spinal cord Injury Research Center, Neuoroscience

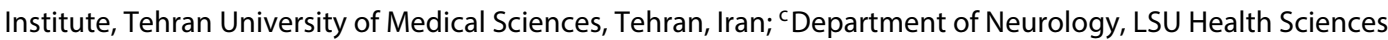 \\ Center, Shreveport, La., USA
}

\section{Key Words}

Multiple sclerosis - Epidemiology · Prevalence · East Asia ·

South East Asia · South Asia

\begin{abstract}
Background: Multiple sclerosis (MS) is one of the most common chronic immune-mediated diseases of the human central nervous system and an important cause of non-traumatic neurologic disability among young population in several countries. Recent reports from East Asia, South East Asia and South Asia have proposed a low to moderate prevalence of MS in these countries. Methods: A literature review search was carried out in December 2014 in Medline, Embase, Scopus and Cochrane library to recover original populationbased studies on MS epidemiology in East Asia, South East Asia and South Asia countries published between January 1, 1950 and December 30, 2014. We intended search strategies using the key words: multiple sclerosis, prevalence, incidence and epidemiology. Based on our inclusion criteria, 68 epidemiologic studies were included in this systematic review. Results: The most extensively used diagnostic criteria in the studies were McDonald's criteria. Most studies were performed in a multi-center hospital setting. The female to
\end{abstract}

male ratio varied and ranged from 0.7 in India to 9.0 in China. The mean age at disease onset ranged from the lowest age of 25.3 in Iran to the highest age of 46.4 in China. MS prevalence ranged from 0.77 in 100,000 populations in Hong Kong (1999) to 85.80 in 100,000 in Iran (2013). Conclusions: Advances in MS registries around the globe allow nationwide population-based studies and will allow worldly comparisons between the prevalence and incidence in different regions that are provided to monitor estimation.

(c) 2016 S. Karger AG, Basel

\section{Background}

Multiple sclerosis (MS) is a chronic immune-mediated disease of the central nervous system, which usually affects young adults [1]. MS is the most important cause of non-traumatic neurologic disability among the young working-class population, resulting in an economical and significant social impact and requiring lifetime support and management $[2,3]$.

According to the main results from the atlas of MS in 2013, the number of patients affected with MS has increased from 2.1 million in 2008 to 2.3 million in 2013 [4].

\section{KARGER}

E-Mail karger@karger.com

www.karger.com/ned
(C) 2016 S. Karger AG, Basel

0251-5350/16/0463-0209\$39.50/0
Mohammad Ali Sahraian

MS Research Center, Neuroscience Institute

Tehran University of Medical Sciences

Tehran (Iran)

E-Mail msahrai@tums.ac.ir 
The prevalence and incidence of MS extensively vary among different countries and various geographical areas. Kurtzke [5] proposed to divide different areas in the world into 3 geographic regions regarding MS prevalence: (1) high $>30 / 100,000$, (2) intermediate (5$25 / 100,000$ ), and (3) low risk $<5 / 100,000$.

Many epidemiological studies have been performed in Europe, north America, Canada and Australia where the prevalence of MS seems to be high, and recent studies show an increase in the disease prevalence in such regions $[4,6]$. According to the globally grouped continent of 101 MS studies from the Americas, Europe, Asia, Africa and Australia/New Zealand, the worldwide median estimated incidence was 5.2 (range 0.5-20.6) per 100,000 personyears, the median estimated prevalence was 112.0 (with a range of 5.2-335) per 100,000 person-years, and the average illness period was 20.2 years (range 7.6-36.2) [7].

There are several epidemiological studies from other parts of the world conducted with different methods and results, which also demonstrate an increase in the number of patients. Countries located in Far East and South Asia were formerly considered to be located in a low prevalence zone for MS $[8,9]$. Recent studies from these regions support the increase in prevalence in such regions. Here, we tried to review the epidemiological studies in Far East and South Asian countries. In this review, we tried to cover all studies conducted in such countries and estimate the latest trends and changes of prevalence and incidence rates of MS among selected countries.

\section{Methods}

\section{Search Strategy}

To determine the epidemiology of MS among countries that constitute Pan Asian Countries Treatment and Research in Multiple Sclerosis; a systematic literatures search of Medline, Embase, Scopus and Cochrane library, which allowed access to publications presented by Tehran University of Medical sciences, using the key words 'multiple sclerosis, prevalence, incidence, epidemiology' and names of countries covering the period between January 1, 1950 and December 30, 2014 was performed.

\section{Screening and Eligibility Criteria}

We utilized computer databases to find population-based studies with information and statistic on MS epidemiology with limitation to general human population studies in English language publications. Cross-sectional and cohort studies were conducted to analyze MS epidemiological features in selected articles. The title and abstract of all literatures recognized by the database were reviewed. The mentioned review of systematic literature was intended to be comprehensive; potentially eligible studies were retrieved and read in full text to confirm that they fulfilled the following inclusion criteria in this systematic review: (1) of population-based studies with human samples among patients with MS measured by different terms of diagnosis criteria in MS among those living in Pan Asian countries; (2) containing data on the prevalence, incidence or number of MS cases in country studies; (3) MS was recognized according to global diagnostic criteria in use at the study period, the Schumacher criteria [10], Poser [11] or McDonald's criteria [12-14]; and (4) available in full text form.

We also conducted a manual hand search of reference lists of primary identified articles and relevant reviews to discover additional studies that could have been missed. The studies that did not represent the general population were excluded. Two experts reviewed the abstracts independently (if the review of abstract did not match the eligibility, the full text was reviewed). All articles that were confirmed by both reviewers for eligibility criteria were considered. Review articles, editorials and letters were excluded. The study selection flowchart was established based on PRISMA (fig. 1).

Our classification of the Pan Asian countries was based on the World Bank classification including the following 34 countries: Japan, China, Mongolia, Hong Kong, North Korea, South Korea, Taiwan, Macau, Cambodia, Indonesia, Lao PDR, Malaysia, Myanmar, Philippines, Thailand, Viet Nam, Brunei, East Timor, Singapore, Fiji, Papua New Guinea, Samoa, Vanuatu, Tonga, Solomon Island, Bhutan, Maldives, Nepal, Sri Lanka, Bangladesh, India, Pakistan, Afghanistan and Iran [15]. Australia and New Zealand are excluded.

Pan-Asian countries were divided into 4 geographical areas such as East Asia, South East Asia, pacific, and South Asia to categorize racial or regional variations in MS across the continent [15]. We have made a comparison from collected data derived from different countries in a tabulated regional form. All abstracts were screened by 2 independent reviewers (if the abstract was not clear for eligibility to be included in the study, the whole full text review was performed) to evaluate whether articles met the including criteria completely. Articles that were considered eligible by both reviewers were retained. The study selection flow diagram was established conferring to PRISMA statement (fig. 1).

\section{Data Extraction and Quality Assessment}

Repeated publications on the same data were excluded. Based on overestimating prevalence, studies were categorized as low, undistinguishable (if data for determination risk was inadequate) or high risk. The quality scores of each study are presented in tables $1-3$.

The following information was elicited into a template form by an expert reviewer: study period, study method, study region, diagnostic criteria, number of cases identified, gender ratio (female to male), onset mean age of disease, prevalence per 100,000 persons, incidence per 100,000 persons and quality score of study. Crude and consistent prevalence and incidence estimation were recorded generally and by gender, county, time length and subgroup as appropriate. Extracted information was considered by a second reviewer and accurate studies data chosen indices were selected for additional meta-analysis. The authors summarized the extracted information from each individual study in a regional table with a consistent pattern. Quality scores are presented in detail in complimentary the tables $1-3$ based on Joanna Briggs critical appraisal tool [16]. 
Fig. 1. PRISMA 2009 flow diagram. Adapted from Moher et al. [98].

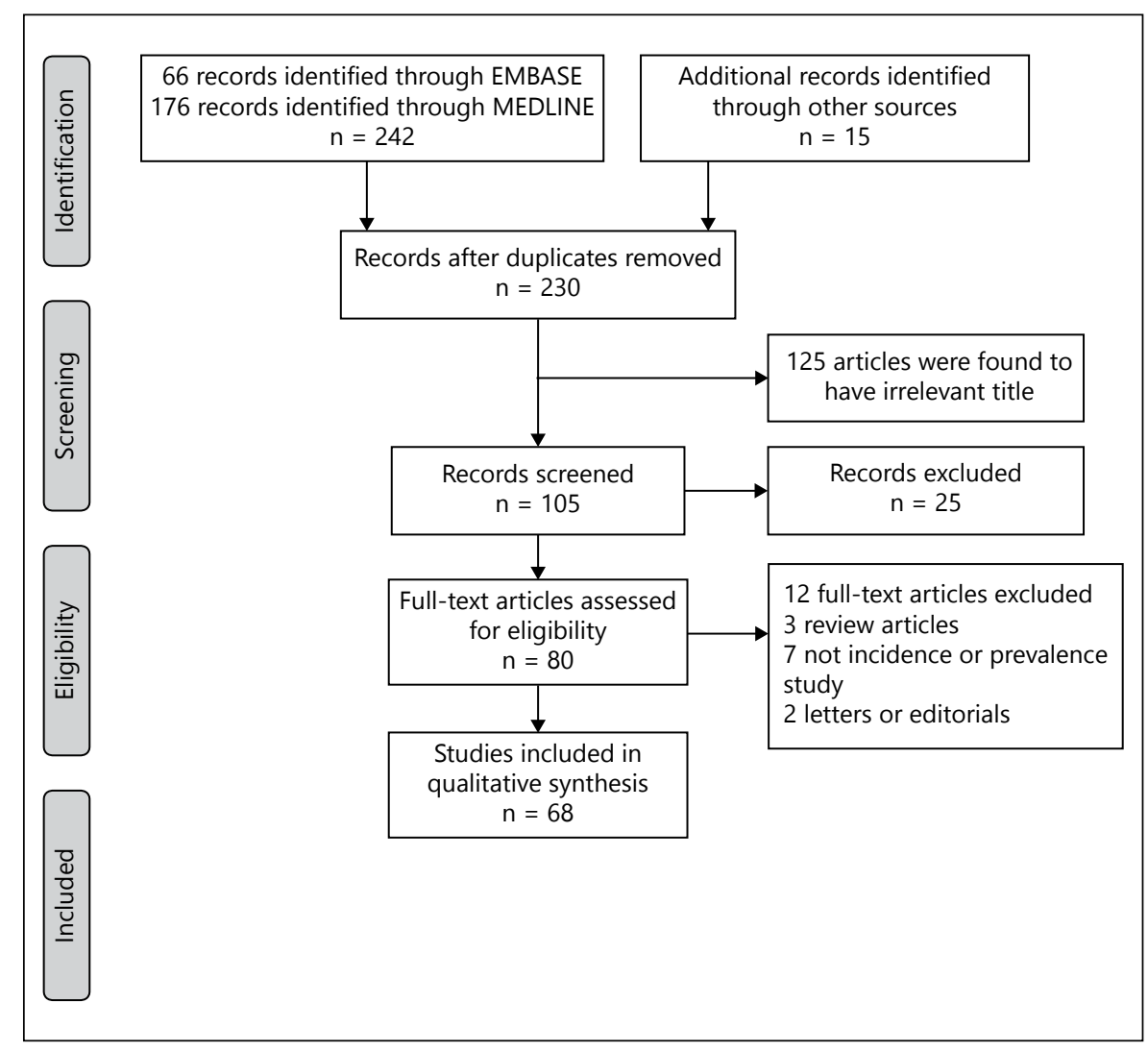

\section{Results}

The search approach obtained a total of 242 appropriate references among all original sources.

After excluding duplicate entries, 230 extensive literatures remained relevant to epidemiological studies of MS in Pan Asian countries. One hundred and twenty five studies had inappropriate titles, and from our screening, 25 studies were not authorized to be part of our study. In this systematic review, finally, 68 studies, excluding 12 full-text articles (number of 4 review articles, 2 editorials or letters and 6 articles which did not indicating incidence and prevalence), were included (fig. 1).

The final analysis included studies from countries such as Japan [17-29], China [30-35], Korea [36-40], Hong Kong [41-44], Taiwan [45-48] in East Asia (table 1), Malaysia [49-51] and Thailand [52-54] in South East Asia (table 2), India [55-62], Pakistan [63, 64] and Iran [65-84] in South Asia (table 3).

There was no result from Mongolia, North Korea, Macau, Cambodia, Indonesia, Lao PDR, Myanmar, Philippines, Viet Nam, Brunei, East Timor, Singapore, Fiji, Papua New Guinea, Samoa, Vanuatu, Tonga,
Solomon Island, Bhutan, Maldives, Nepal, Sri Lanka, Bangladesh and Afghanistan. It was found that latest studies had higher quality in terms of content, with inclusion of the McDonald criteria. Tables 1-3 show the study duration, study method, study setting, diagnostic criteria, population size, gender (female to male ratio), mean age at disease onset, prevalence and incidence rates in selected studies.

McDonald's diagnostic criteria were the most extensively used diagnostic criteria in the studies (51.56\%); in the second level, Poser criteria were used in $38.38 \%$ of studies and Schumacher criteria were used in 14.06 of studies.

The information source to obtain patient report in $36.8 \%$ of studies was used from regional MS registries, while $38.2 \%$ of information reported was based on a multi-center hospital setting and $25 \%$ of studies were based on a single-hospital setting.

Female to male sex ratio is very diverse ranging among different studies in this region, from 0.7 in India to 9.0 in China (tables 1, 3).

In general, we estimated a female to male ratio of 3.6 in this region, after including 38 studies and after consid- 


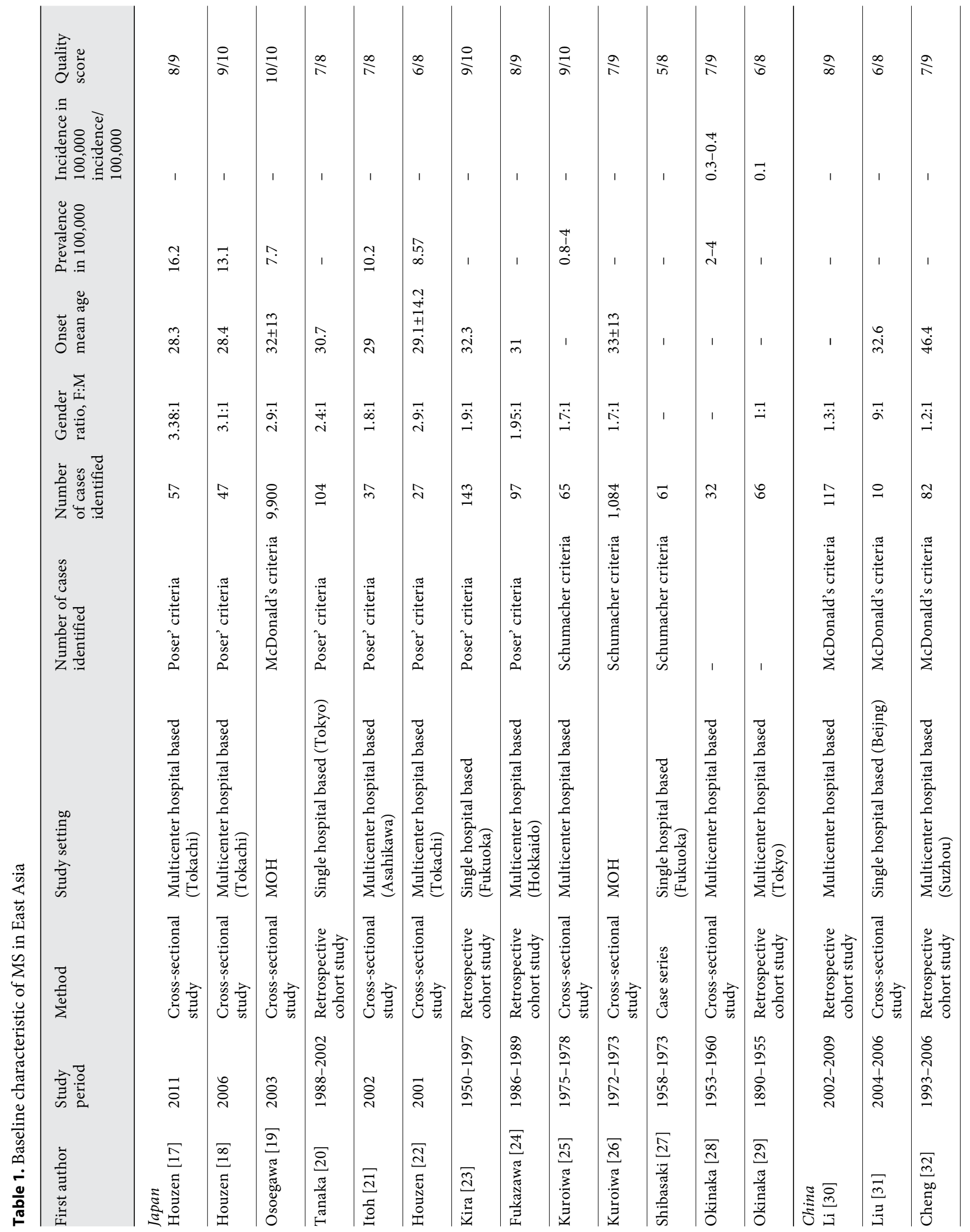




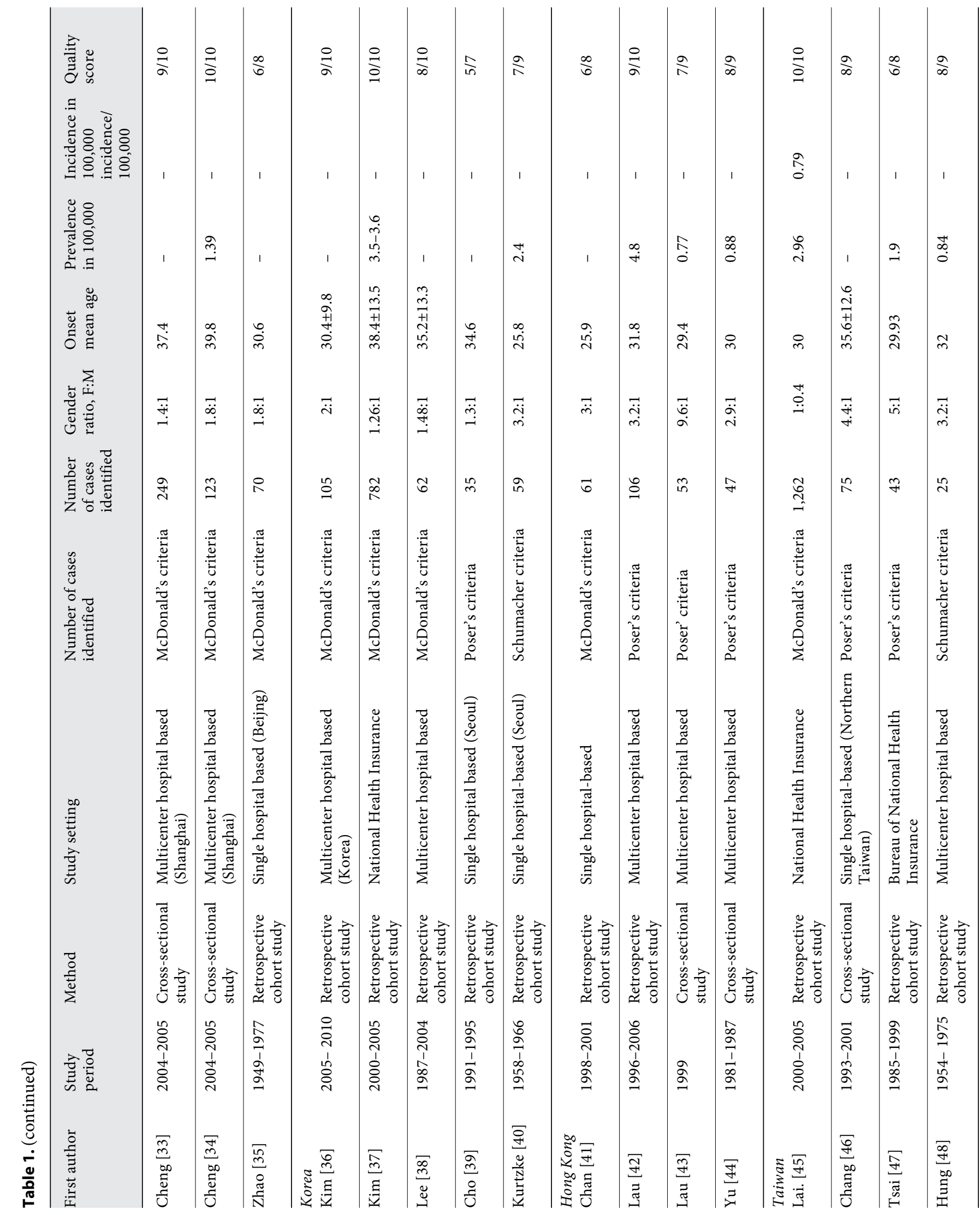




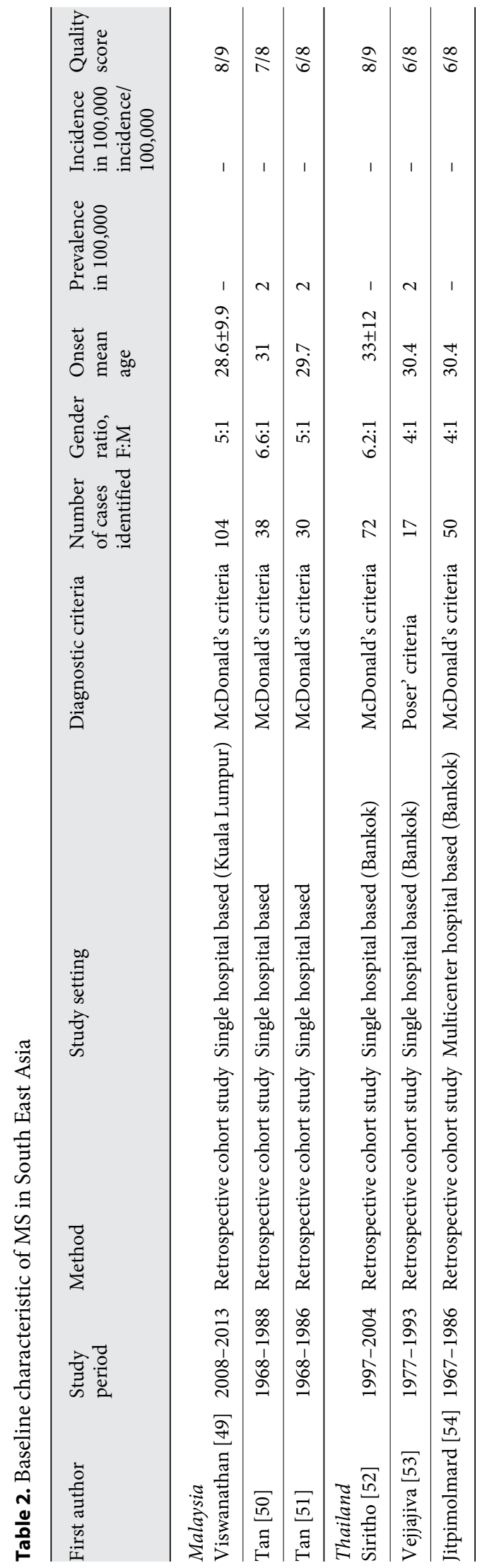

ering that the number of cases affecting sex ratio to be larger than 70 cases. The results of female to male ratio is 3.4:1 in East Asia following, 2.1 in Japan, 1.5:1 in China, 1.6:1 in Korea, 3.2:1 in Hong Kong and 3.4:1 in Taiwan (table 1). The results of female to male ratio are 5.6 in South East Asia following, 5.1:1 in Malaysia and 6.2:1 in Thailand (table 2). The result of female to male ratio is 1.9:1 in South Asia following, 3.0:1 in Iran, 1.4:1 in Pakistan and 1.3:1 in India (table 3).

Prevalence estimation of MS was more frequent than incidence estimation of MS. The mean age at disease onset range was 21.1 in these countries, with a maximum value of 46.4 in China to a minimum of 25.3 in Iran (tables $1,3)$.

In this segment, we present a brief report of MS epidemiology in selected countries by each region.

\section{East Asia \\ Japan}

According to our review, a large increase in prevalence was observed during the last decade from 7.7 in 2003 in the Tokachi province of Hokkaido in Northern Japan to 13.1 in 2006 and 16.2 in 2011 respectively in the same area $[17,18]$. Several national surveys on MS were performed in Japan in 1972, 1982, 1989, and 2004 [19, 26, 85]; the 2004 survey was carried out by the Research Committees of Epidemiology of Intractable Diseases and Neuroimmunological Diseases. The critical information was collected in 2 phases: the first phase was about recognizing the MS patient population, and the second step was about sending self-report questionnaires to all the treated MS patients in the selected hospitals from January 1, 2003 to December 31, 2003 [19]. In Japan, the MS estimated prevalence was 7.7 in a population of 100,000 people $(95 \%$ CI 7.1-8.4) [19]. Our current survey indicated the increasing female to male sex ratio of MS over 50 years from 1:1 in 1955 to 3.38:1 in 2011. The mean age at disease onset had decreased from $33 \pm 13$ in 1972 to 28.3 in 2011. In Japan, certain explanations for a decline in the mean age include more frequent utilization of MRI imaging as well as improved neurological care [17].

\section{China}

Cheng et al. [33] reported the MS prevalence of 1.39 per 100,000 (95\% CI 1.16-1.66) in Shanghai. All studies used McDonald's criteria as diagnostic criteria among MS patients. In our reviewed studies, MS prevalence is more common among females in comparison to males $[30-33,35]$. In the last 2 decades, the mean age at disease onset ranged from 46.4 in 1993 to 32.6 in 2006 [31, 32]. 


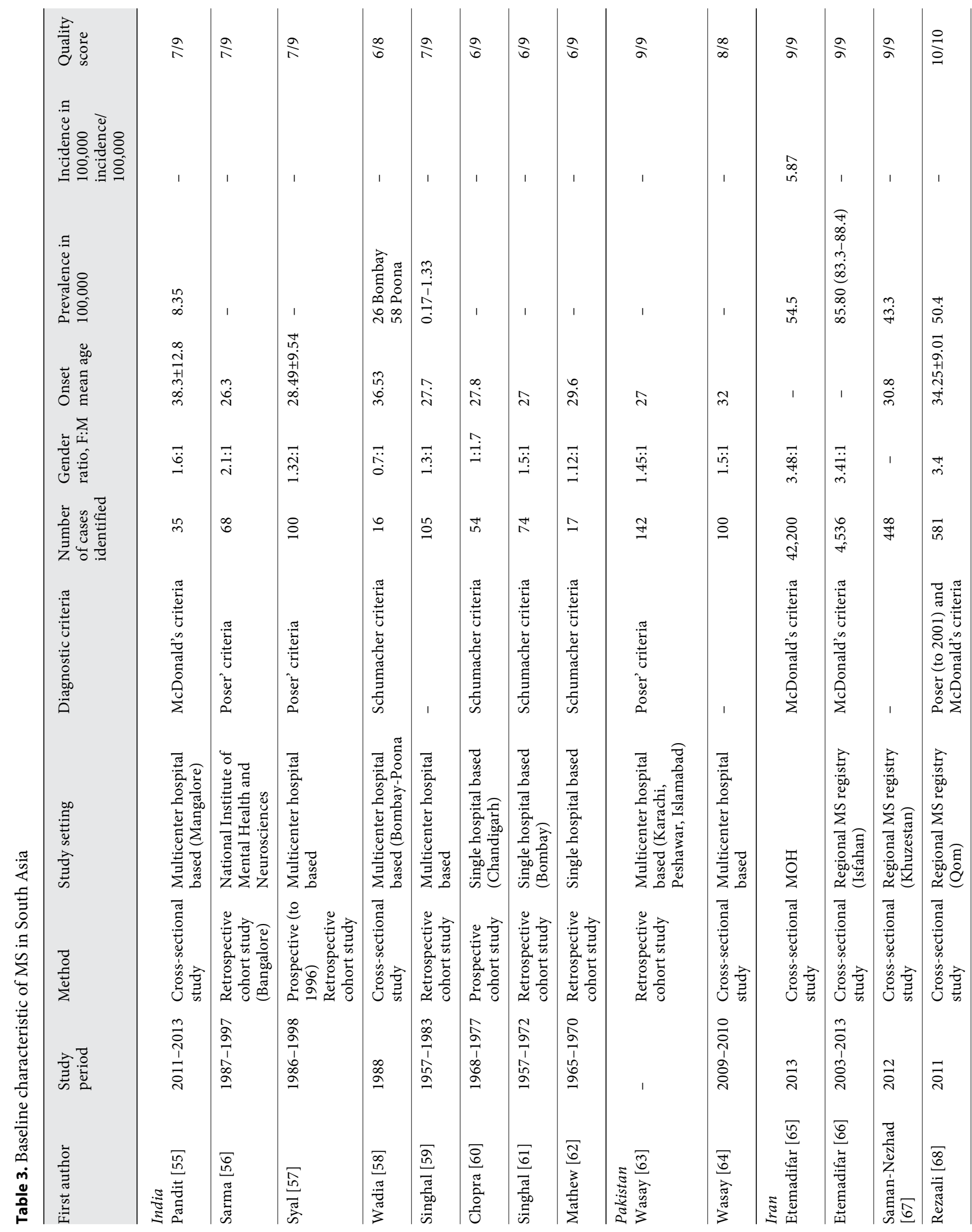




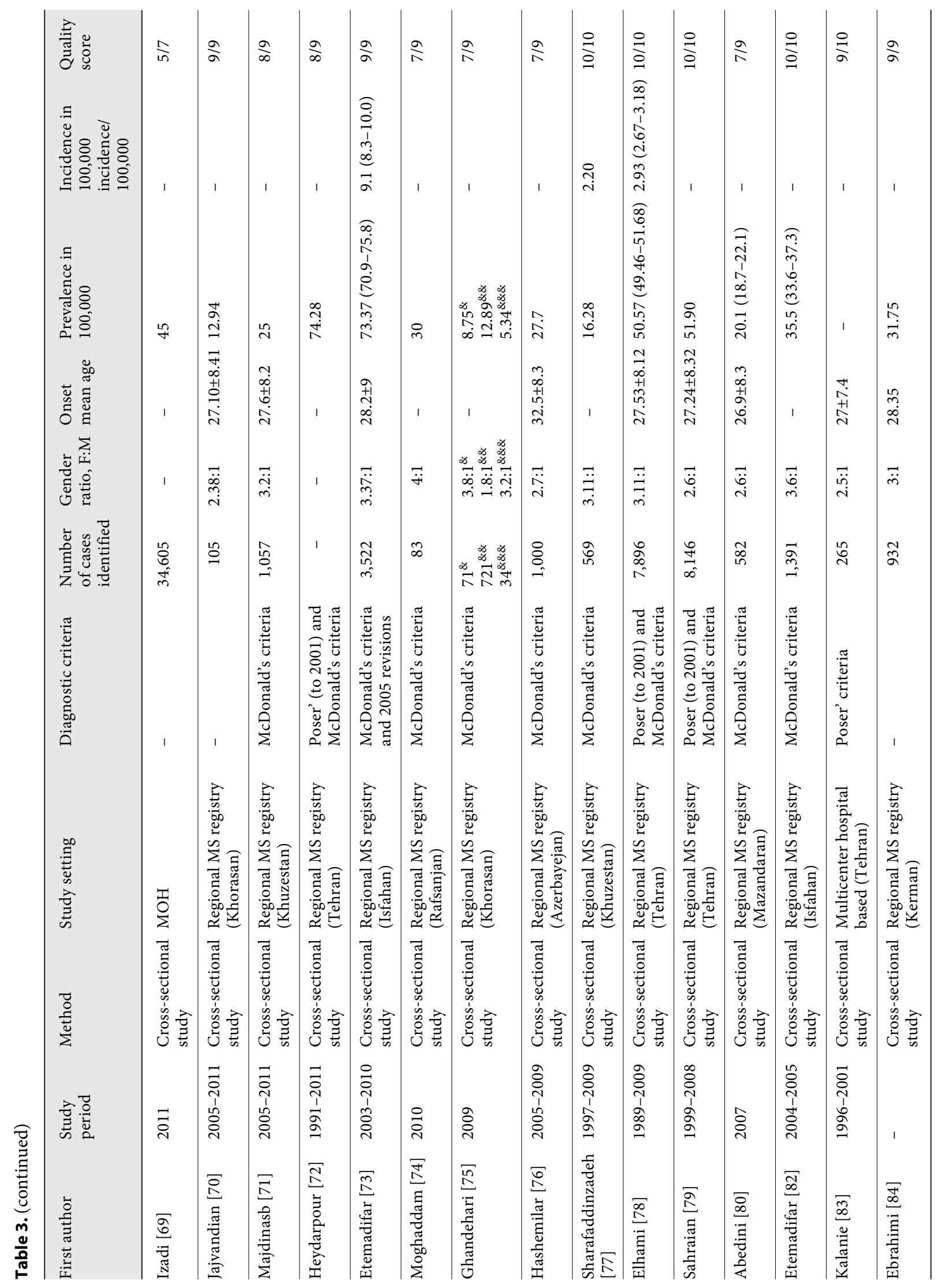


Li et al. [30] reported that amongst those with MS, the number of patients with opticospinal MS (OSMS) was higher in Northern China compared to Western countries, and limb weakness at onset was the most popular medical symptom in both OSMS and CMS patients.

Korea

The prevalence of MS in Korea was estimated to be 3.5-3.6 per 100,000 people [37]. The clinical pattern of MS in Korea is similar from that observed in other Asian countries [38].

A nationwide survey from 2000 to 2005 in Korea, utilizing several databases gathered from 38 main referral hospitals has shown an MS prevalence of 3.5-3.6 in 100,000 population [37]. Another study in Seoul, estimated the prevalence of MS to be 2.4 in 100,000 people [40]. MS is more common among women and female to male ratio is $2: 1$.

The mean age of onset decreased from 35.2 in 19872004 to 30.4 in 2005-2010 [36, 38].

According to the involved location, the most prominent detection that is of concern is the involvement of $78 \%$ of the spinal cord and $25 \%$ of the optic nerve among MS patients in Korea [36].

\section{Hong Kong}

Prevalence of MS among Hong Kong patients was estimated to be from 0.77 to 4.8 per 100,000 populations $[42,44]$. Studies of MS among Chinese patients in Hong Kong indicated a worse clinical outcome of Chinese MS patients than that of Caucasian patients [42]. Epidemiological MS study in Hong Kong showed that there were 95 relapsing-remitting (RR) type, 7 progressive relapsing type and 4 primary progressive (PP) type among $106 \mathrm{pa}-$ tients [42]. Female to male sex ratio ranged from 9.6:1 in 1999 to $3: 1$ in 2001 [41, 42]. The mean age at onset disease decreased from 31.8 to 25.9 [41, 42].

\section{Taiwan}

The prevalence of MS increased in recent decades from 0.84 in 1975 and 1.9 in 1999 to 2.96 in 100,000 population in 2005 [45, 47, 48]. According to our review, the incidence of MS in Taiwan is 0.79 [45]. MS incidence was found to be the highest for females in the age group of $40-60$ and for males in the age group of over 55 [45]. Female MS patients outnumbered males by a ratio of 2.5:1 [45].

Regarding gender, the female-to-male ratio in Taiwan is higher than it is in Western countries [86]. Among 1962 MS patients, the mean age at onset was 30 [45], and for
OSMS, the mean age at onset was 41.88 . The anatomic area that was consistently affected was the spinal cord (48\%), followed by the optic nerve (33\%). The most common type of MS is RR in $51 \%$ of the patients, and it takes a secondary-progressive (SP) and PP course in 30 and $19 \%$ of MS patients, respectively [47].

\section{South East Asia}

Malaysia

The Malaysian populations were affected by Chinese, Indians and other native racial groups [49]. Malaysia has been considered low risk area for MS. The prevalence of MS was 2 per 100,000 populations, and the young age group remained the most frequently affected with a mean age at onset of $28.6 \pm 9.9$ [50]. A high female to male ratio in MS has been reported in Malaysia [50, 51]. A 6-year hospital-based study on 104 MS patients in Kuala Lumpur revealed that $89.4 \%$ of patients had the RR type, followed by $5.8 \%$ of SP and $2.9 \%$ PP course of disease [49]. Among all patients, $5 \%$ had a family history of MS. The prevalence pattern of this type of multiple MS in Malaysia is steadily changing with regard to racial distribution. The result of epidemiological study in Malaysia disclosed that the Chinese have more neuromyelitis optica and its spectrum disorders rather than MS [49].

\section{Thailand}

No population-based epidemiological study has been performed to estimate the incidence and prevalence of MS in Thailand. According to a single-based hospital study in Bangkok from 1977-1993, the prevalence of MS is 2 in 100,000 population [53]. Siritho et al. [52] reported the mean age to be $33 \pm 12$ during the onset of MS.

Among $72 \mathrm{MS}$ patients, the female to male ratio was estimated to be 6.2:1. None of the patients had reported MS among members in their family [52].

The main body parts that got affected due to MS attacks among patients in Thailand was the optic nerve, which got affected by $51 \%$, followed by $26 \%$ in spinal cord, $19 \%$ brainstem, $1 \%$ cerebral hemisphere and $1 \%$ optic-spinal respectively [52].

\section{South Asia}

India

There is no large epidemiological study in MS from India. Based on multicenter hospital-based statistics, the prevalence of MS increased from 1.33/100,000 to 8.35 in last 30 years $[55,59]$. Female to male ratio was $1.6: 1$ and the mean age at onset was 38.3 [55]. 
Syal et al. [57] reported that RR course among $89 \%$ of MS patients followed a progressive course in $11 \%$ from the time the disease began. The OSMS was common among $71.4 \%$ of patients [59].

Pakistan

There are no population-based studies concerning prevalence or incidence for MS from Pakistan.

A multicenter hospital database from Karachi, Peshawar and Islamabad among $142 \mathrm{MS}$ patients estimated that the mean age at onset was 27 years, with a female to male ratio of 1.45:1 [63].

The RR course of MS has been seen in $81 \%, \mathrm{PP}$ in $21 \%$, and SP in $4 \%$ of patients [63].

Iran

Based on the ministry of health report in Iran, the prevalence of MS increased from 45/100,000 in 2011 to $54.5 / 100,000$ in $2013[65,69]$.

In capital city, Tehran, MS prevalence had increased to $74.28 / 100,000$ in 2011 from 51.9/100,000 in 2008 [72, 79].

The annual crude incidence of MS had significantly increased from 3.77 in 2007 to 5.68/100,000 in 2013 [65]. In Iran, a higher prevalence of MS was reported from Isfahan [66].

Based on regional MS registry studies in Isfahan, the general increase in MS prevalence and incidence occurred over a decade; MS prevalence had increased from 35.5 in 2005 to 85.8 per 100,000 in 2013 and incidence had increased from 3.64 in 2006 to 9.1 in 2010 [66, 73, 81, 82].

The MS is over 3 times more common in females than in males [65]. Among MS patients, RR was reported in $84.9 \%$. The onset mean age of disease was 27.24; positive family history of MS was recognized in $9.5 \%$ of patients in Khorasan and $12.2 \%$ of patients in Isfahan $[69,75$, 76].

The most common clinical course among $87.8 \%$ of MS patients was RRMS; 6.4\% had SPMS and 5.7\% had PPMS. First appearance was sensory in $51.7 \%$ and visual disturbances were reported in $47.5 \%$ of patients. The lowest mean age at disease onset was 25.36 in Isfahan and the highest was 34.25 years in Qom [66, 73, 81, 82, 87].

Iran has reported variable prevalence rates of MS from different regions, the prevalence rate per 100,000 population in North Iran, Mazandaran was 20.1 [80], 27.7 in Northwest, Azerbaijan [76], 12.94 in Northeast, Khorasan [70], 16.28 in Southwest Iran, in Khuzestan [77], in central, Qom 50.4 and 31.7 in Kerman [68, 84].

\section{Discussion}

This study presents a systematic and inclusive review of 68 MS epidemiological studies in Asia. Our results are greatly restricted by the limitation of existing data, which could influence prevalence, incidence, gender ratio and the mean age at MS onset. Nationwide epidemiological studies were rare in Pan Asian countries. In addition, the different studies are bound by the variable quality of data, small number of cases identified, different diagnostic criteria and variable publication methods. Our study was restricted to only English. There are several studies in different languages, which are not possible to access because of translational difficulties.

The method for study and type of population collection were heterogeneous. Few studies estimated the incidence rate in 100,000 populations.

The key significant findings are as follows: (1) the first extensively used diagnostic criteria among these studies was McDonald's criteria. (2) The performance of a greater part of studies was in multi center hospital-based setting. (3) Generally female to male ratio was 3.6 in this region. (4) MS prevalence rate per 100,000 populations was 12.48 in this region. (5) The mean age of disease onset was 21.1 .

The results of selected Asian countries were divided into 3 geographical regions (East Asia, Southeast Asia and South Asia). MS prevalence was low in the East and Southeast Asia compared to South Asia. Another study showed that MS prevalence is low in East and South Asia compared to West Asia and the Middle East [9]. Based on a study done by Kurtzke et al. [88], in 1995, the prevalence of MS was moderate (5-29/100,000) in these regions similar to Russia, Ukraine, the South Africa, the South America.

MS prevalence in East Asian countries was low and estimated to be $0.8-2$ per 100,000 population [89]. MS prevalence was high in West Asia compared to East and South Asia. MS is described to be of low prevalence among the Chinese people in comparison with other Asian countries during the last decade [33].

An increase in prevalence has also been observed in other Asian countries, such as Kuwait and Jordan [90-92] but the prevalence was much lower than in European countries [93].

In the past few decades, the global prevalence and incidence patterns of MS have changed dramatically. The recent global classification of MS also indicated worldwide increase in the prevalence of MS [7].

Female to male sex ratio is high among patients in Hong Kong, Malaysia and Thailand similar to that in the 
United States $[42,50,52,94]$ when compared to the estimation of female to male ratio among countries in Europe [95].

The data point out that MS is higher in females than in males. Generally, increasing MS incidence among women in many countries can lead to higher female to male sex ratios of MS in region and this similar tendency was observed in Canada [96].

The prevalence and incidence of MS vary in different parts of Asia; however, the limited nationwide epidemiological data, weak responsiveness and limited diagnostic facilities have significantly influenced the reporting of MS in many countries in the region. Some Asian countries, including Iran and Japan, have reported an increased prevalence of MS in the last decade [17, 66].

Several studies have shown that MS is not well recognized in the Asian region. It is indicative of lack of knowledge about MS in comparison to Western countries. The national epidemiological survey information is not available, and MS prevalence may be under-estimated [8].

Analysis of MS baseline characteristic in present studies among Asian countries indicates an important task of the MS regional or national registry system for an accurate and uniform estimation of MS. The importance of these data establishment is helpful for monitoring the term and trend of MS and its characteristics in whole country populations [97].
The availability of neurologists and diagnostic tools has a strong link to MS diagnosis; consequently, the prevalence of MS may increase in this region while accessibility to these services becomes more extensive [95]. According to the Atlas of MS in 2013, the median number of neurologists per 100,000 populations is only 0.03 for low-income-group countries compared with 3.6 for high-income-group countries. The number of MRI machines that existed in 2008 has doubled in 2013 in lowincome, lower-middle-income and upper-middle income countries, while still there are many differences between the number of MRI instruments in different countries.

While the number of MRI machines per 100,000 populations worldwide is 0.46 per 100,000 in 2013 , the number of MRI machines in high-income, upper-middle-income countries is 1.6 and 0.4 per 100,000 populations and in lower-middle-income and low-income-countries is 0.01 per 100,000 populations.

Notably, most countries selected for our studies were belonged to the category of low income and lower middle income [4].

\section{Disclosure Statement}

Authors declare no conflict of interest.

\section{References}

1 Marrie R, Horwitz RI: Emerging effects of comorbidities on multiple sclerosis. Lancet Neurol 2010;9:820-828.

2 Benamer H, Ahmed ES, Al-Din AS, Grosset DG: Frequency and clinical patterns of multiple sclerosis in Arab countries: a systematic review. J Neurol Sci 2009;278:1-4.

3 Cristiano E, Patrucco L, Rojas JI: A systematic review of the epidemiology of multiple sclerosis in South America. Eur J Neurol 2008; 15:1273-1278.

4 Bowne P, Chandraratna D, Angood C, Tremlett $\mathrm{H}$, Baker C, Taylor BV, Thompson AJ, et al: Atlas of multiple sclerosis 2013: a growing global problem with widespread inequity. Neurology 2014;83:1022-1024.

5 Kurtzke JF: Epidemiologic contributions to multiple sclerosis: an overview. Neurology 1980;30(7 pt 2):61-79.

6 Evans C, Beland SG, Kulaga S, Wolfson C, Kingwell E, Marriott J, et al: Incidence and prevalence of multiple sclerosis in the Americas: a systematic review. Neuroepidemiology 2013;40:195-210.

7 Melcon MO, Correale J, Melcon CM: Is it time for a new global classification of mul- tiple sclerosis? J Neurol Sci 2014;344:171181.

8 Kira J: Multiple sclerosis in the Japanese population. Lancet Neurol 2003;2:117-127.

9 Wasay M, Khatri IA, Khealani B, Sheerani M: MS in Asian countries. Int MS J 2006;13:5865.

10 Schumacher GA, Beebe G, Kibler RF, Kurland LT, Kurtzke JF, McDowell F, Nagler B, Sibley WA, Tourtellotte WW, Willmon TL: Problems of experimental trials of therapy in multiple sclerosis: report by the panel on the evaluation of experimental trials of therapy in multiple sclerosis. Ann N Y Acad Sci 1965; 122:552-568.

11 Poser CM, Paty DW, Scheinberg L, McDonald WI, Davis FA, Ebers GC, et al: New diagnostic criteria for multiple sclerosis: guidelines for research protocols. Ann Neurol 1983;13:227231.

12 McDonald WI, Compston A, Edan G, Goodkin D, Hartung HP, Lublin FD, et al: Recommended diagnostic criteria for multiple sclerosis: guidelines from the international panel on the diagnosis of multiple sclerosis. Ann Neurol 2001;50:121-127.
13 Polman CH, Reingold SC, Edan G, Filippi M, Hartung HP, Kappos L, et al: Diagnostic criteria for multiple sclerosis: 2005 revisions to the 'McDonald criteria'. Ann Neurol 2005;58: 840-846.

14 Polman CH, Reingold SC, Banwell B, Clanet M, Cohen JA, Filippi M, et al: Diagnostic criteria for multiple sclerosis: 2010 revisions to the McDonald criteria. Ann Neurol 2011;69: 292-302.

15 The World Bank. http://data.worldbank.org/ country.

16 Munn Z, Moola S, Riitano D, Lisy K: The development of a critical appraisal tool for use in systematic reviews addressing questions of prevalence. Int J Health Policy Manag 2014;3: 123-128.

17 Houzen H, Niino M, Hirotani M, Fukazawa $\mathrm{T}$, Kikuchi S, Tanaka K, et al: Increased prevalence, incidence, and female predominance of multiple sclerosis in northern Japan. J Neurol Sci 2012;323:117-122.

18 Houzen H, Niino M, Hata D, Nakano F, Kikuchi S, Fukazawa T, et al: Increasing prevalence and incidence of multiple sclerosis in northern Japan. Mult Scler 2008; 14:887-892. 
19 Osoegawa M, Kira J, Fukazawa T, Fujihara K, Kikuchi S, Matsui M, et al: Temporal changes and geographical differences in multiple sclerosis phenotypes in Japanese: nationwide survey results over 30 years. Mult Scler 2009;15: 159-173.

20 Tanaka K, Kujuro Y, Suzuki S, Tanahashi N, Hamada J, Nogawa S, et al: Clinical and laboratory features of in-patients with multiple sclerosis in a University Hospital in Tokyo from 1988-2002. Intern Med 2005;44:560566.

21 Itoh T, Aizawa H, Hashimoto K, Yoshida K, Kimura T, Katayama T, Koyama S, et al: Prevalence of multiple sclerosis in Asahikawa, a city in northern Japan. J Neurol Sci 2003;214: 7-9.

22 Houzen H, Niino M, Kikuchi S, Fukazawa T, Nogoshi S, Matsumoto $\mathrm{H}$, et al: The prevalence and clinical characteristics of MS in northern Japan. J Neurol Sci 2003;211:49-53.

23 Kira J, Yamasaki K, Horiuchi I, Ohyagi Y, Taniwaki T, Kawano Y: Changes in the clinical phenotypes of multiple sclerosis during the past 50 years in Japan. J Neurol Sci 1999; 166:53-57.

24 Fukazawa T, Tashiro K, Hamada T, Moriwaka F, Matsumoto A, Shima K, et al: Multiple sclerosis in Hokkaido, the Northernmost Island of Japan: prospective analyses of clinical feature. Intern Med 1992;31:349-352.

25 Kuroiwa Y, Shibasaki H, Ikeda M: Prevalence of multiple sclerosis and its north-to-south gradient in Japan. Neuroepidemiology 1983; 2:62-69.

26 Kuroiwa Y, Igata A, Itahara K, Koshijima S, Tsubaki T: Nationwide survey of multiple sclerosis in Japan. Clinical analysis of 1,084 cases. Neurology 1975;25:845-851.

27 Shibasaki H, Kuroda Y, Kuroiwa Y: Clinical studies of multiple sclerosis in Japan: classical multiple sclerosis and Devic's disease. J Neurol Sci 1974;23:215-222.

28 Okinaka S, Tsubaki T, Kuroiwa Y, Toyokura Y, Imamura Y: Multiple sclerosis and allied diseases in Japan; clinical characteristics. Neurology 1958;8:756-763.

29 Okinaka S, Kurowia Y: Multiple sclerosis and allied diseases in Japan: epidemiological and clinical aspects. Prog Brain Res 1966;21:183191.

30 Li T, Xiao H, Li S, Du X, Zhou J: Multiple sclerosis: clinical features and MRI findings in northern China. Eur J Med Res 2014;19:20.

31 Liu Y, Duan Y, Yu C, Qin W, Chen H, Dong $\mathrm{H}$, et al: Clinical isolated syndrome: a 3-year follow-up study in China. Clin Neurol Neurosurg 2011;113:658-660.

32 Cheng X, Cheng Q, Xu LZ, Zhao HQ, Zhao Z, Wang W, et al: Evaluation of multiple sclerosis diagnostic criteria in Suzhou, China - risk of under-diagnosis in a low prevalence area. Acta Neurol Scand 2010;121:24-29.

33 Cheng Q, Miao L, Zhang J, Ding SJ, Liu ZG, Wang X, et al: A population-based survey of multiple sclerosis in Shanghai, China. Neurology 2007;68:1495-1500
34 Cheng Q, Miao L, Zhang J, Guan YT, Liu ZG, Wang X, et al: Clinical features of patients with multiple sclerosis from a survey in Shanghai, China. Mult Scler 2008;14:671-678.

35 Zhao B, Liu XQ, Guo YP, Yang YC, Huang HF: Multiple sclerosis. A clinical study of 70 cases. Eur Neurol 1981;20:394-400.

36 Kim S, Huh SY, Kim W, Park MS, Ahn SW, Cho JY, et al: Clinical characteristics and outcome of multiple sclerosis in Korea: does multiple sclerosis in Korea really differ from that in the Caucasian populations? Mult Scler 2013;19:1493-1498.

37 Kim NH, Kim HJ, Cheong HK, Kim BJ, Lee $\mathrm{KH}$, Kim EH, et al: Prevalence of multiple sclerosis in Korea. Neurology 2010;75:14321438.

38 Lee SS, Sohn EH, Nam SW: Preliminary studies on the clinical features of multiple sclerosis in Korea. J Clin Neurol 2006;2:231-237.

39 Cho Y, Jeon B, Kim Y, Chang K: Clinical features and outcomes from diagnostic work-up in definite multiple sclerosis. J Korean Neurol Assoc 1999;17:823-828.

40 Kurtzke J, Park C, Oh S: Multiple sclerosis in Korea. Clinical features and prevalence. J Neurol Sci 1968;6:463-481.

41 Chan KH, Tsang KL, Ho PW, Tse CT, Kwan JS, Ho JW, et al: Clinical outcome of relapsing remitting multiple sclerosis among Hong Kong Chinese. Clin Neurol Neurosurg 2011; 113:617-622.

42 Lau K, Wong W, Sheng B, Yu I, Fung B, Li H, et al: The clinical course of multiple sclerosis patients in Hong Kong. J Neurol Sci 2008;268: 78-82.

43 Lau KK, Wong LK, Li LS, Chan YW, Li HL, Wong V: Epidemiological study of multiple sclerosis in Hong Kong Chinese: questionnaire survey. Hong Kong Med J 2002;8:77-80.

$44 \mathrm{Yu}$ Y, Woo E, Hawkins BR, Ho HC, Huang CY: Multiple sclerosis amongst Chinese in Hong Kong. Brain 1989;112(pt 6):1445-1467.

45 Lai CH, Tseng HF: Population-based epidemiological study of neurological diseases in Taiwan: I. Creutzfeldt-Jakob disease and multiple sclerosis. Neuroepidemiology 2009;33: 274-253.

46 Chang KH, Lyu RK, Chen CM, Hsu WC, Wu YR, Chen ST, et al: Clinical characteristics of multiple sclerosis in Taiwan: a cross-sectional study. Mult Scler 2006;12:501-506.

47 Tsai CP, Yuan CL, Yu HY, Chen C, Guo YC, Shan DE: Multiple sclerosis in Taiwan. J Chin Med Assoc 2004;67:500-505.

48 Hung TP, Landsborough D, Hsi MS: Multiple sclerosis amongst Chinese in Taiwan. J Neurol Sci 1976;27:459-484.

49 Viswanathan S, Rose N, Masita A, Dhaliwal JS, Puvanarajah SD, Rafia MH, et al: Multiple sclerosis in Malaysia: demographics, clinical features, and neuroimaging characteristics. Mult Scler Int 2013;2013:614716.

50 Tan CT: Multiple sclerosis in Malaysia. Neurol J Southeast Asia 1997;2:1-5.

51 Tan CT: Multiple sclerosis in Malaysia. Arch Neurol 1988;45:624-627.
52 Siritho S, Prayoonwiwat N: A retrospective study of multiple sclerosis in Siriraj Hospital, Bankok, Thailand. Can J Neurol Sci 2007;34: 99-104.

53 Vejjajiva A: Multiple sclerosis in Thailand. Neurol J Southeast Asia 1977;2:7-10.

54 Jitpimolmard S, Vejjajiva A: Clinical features and clinical course of multiple sclerosis in Thai patients: a report of 50 cases. J Med Assoc Thai 1994;77:239-243.

55 Pandit L, Kundapur R: Prevalence and patterns of demyelinating central nervous system disorders in urban Mangalore, South India. Mult Scler 2014;20:1651-1653.

56 Sarma GRK, Nagaraj D: Multiple sclerosis in South India. Ann Indian Acad Neurol 2005;8: 71-74.

57 Syal P, Prabhakar S, Thussu A, Sehgal S, Khandelwal N: Clinical profile of multiple sclerosis in north-west India. Neurol India 1999;47:12-17.

58 Wadia NH, Bhatia K: Multiple sclerosis is prevalent in the Zoroastrians (Parsis) of India. Ann Neurol 1990;28:177-179.

59 Singhal BS: Multiple sclerosis. Neurol India 1999;47:1-2.

60 Chopra JS, Radhakrishnan K, Sawhney BB, Pala N, Banerjee A: Multiple sclerosis in North-West India. Acta Neurol Scand 1980 62:312-321.

61 Singhal BS, Wadia NH: Profile of multiple sclerosis in the Bombay region. On the basis of critical clinical appraisal. J Neurol Sci 1975; 26:259-270.

62 Mathew NT, Mathai KV, Abraham J, Taori GM: Incidence and pattern of demyelinating disease in India. J Neurol Sci 1971;13:27-38.

63 Wasay M, Ali S, Khatri IA, Hassan A, Asif M, Zakiullah N, et al: Multiple sclerosis in Pakistan. Mult Scler 2007;13:668-669.

64 Wasay M, Rizvi F, Azeemuddin M, Yousuf A, Fredrikson S: Incidental MRI lesions suggestive of multiple sclerosis in asymptomatic patients in Karachi, Pakistan. J Neurol Neurosurg Psychiatry 2011;82:83-85.

65 Etemadifar M, Izadi S, Nikseresht A, Sharifian M, Sahraian MA, Nasr Z: Estimated prevalence and incidence of multiple sclerosis in Iran. Eur Neurol 2014;72:370-374.

66 Etemadifar M, Abtahi SH, Akbari M, Murray RT, Ramagopalan SV, Fereidan-Esfahani M: Multiple sclerosis in Isfahan, Iran: an update. Mult Scler 2013;20:1145-1147.

67 Saman-Nezhad B, Rezaee T, Bostani A, Najafi F, Aghaei A: Epidemiological characteristics of patients with multiple sclerosis in Kermanshah, Iran in 2012. J Mazandaran Univ Med Sci 2013;23:97-101.

68 Rezaali S, Khalilnezhad A, Naser Moghadasi A, Chaibakhsh S, Sahraian MA: Epidemiology of multiple sclerosis in Qom: demographic study in Iran. Iran J Neurol 2013;12:136-143.

69 Izadi S, Nikseresht A, Sharifian M, Sahraian MA, Hamidian Jahromi A, Aghighi M, et al: Significant increase in the prevalence of multiple sclerosis in Iran in 2011. Iran J Med Sci 2014;39:152-153. 
70 Jajvandian R, Ali Babai A, Torabzadeh S, Rakhshi N, Nikravesh A: Prevalence of multiple sclerosis in North Khorasan province, northern Iran. $5^{\text {th }}$ Joint Triennial Congress of the European and Americas Committees for Treatment and Research in Multiple Sclerosis. Amsterdam, 2011, pp S84-S85.

71 Majdinasab N. Nakhostin-Mortazavi A, Alemzadeh-Ansari MH: Epidemiologic features of multiple sclerosis in south-western Iran. $28^{\text {th }}$ Congress of the European Committee for Treatment and Research in Multiple Sclerosis. Lyon, Multiple Sclerosis, 2012, p 311.

72 Heydarpour P, Mohammad K, Yekaninejad MS, Elhami SR, Khoshkish S, Sahraian MA: Multiple sclerosis in Tehran, Iran: a joinpoint trend analysis. Mult Scler 2014;20:512.

73 Etemadifar M, Maghzi AH: Sharp increase in the incidence and prevalence of multiple sclerosis in Isfahan, Iran. Mult Scler 2011;17: 1022-1027.

74 Moghaddam AH. Iranmanesh F, Vakilian A: Epidemiology of multiple sclerosis in Rafsanjan: south of Iran. Mult Scler J 2013;650.

75 Ghandehari K, Riasi HR, Nourian A, Boroumand AR: Prevalence of multiple sclerosis in north east of Iran. Mult Scler 2010;16:15251526.

76 Hashemilar M, Savadi Ouskui D, Farhoudi M, Ayromlou H, Asadollahi A: Multiple sclerosis in east Azerbaijan, north west Iran. Neurol Asia 2011;16:127-131.

77 Sharafaddinzadeh N, Moghtaderi A, Majdinasab N, Dahmardeh M, Kashipazha D, Shalbafan B: The influence of ethnicity on the characteristics of multiple sclerosis: a local population study between Persians and Arabs. Clin Neurol Neurosurg 2013;115:12711275.
78 Elhami SR, Mohammad K, Sahraian MA, Eftekhar H: A 20-year incidence trend (19892008) and point prevalence (March 20, 2009) of multiple sclerosis in Tehran, Iran: a population-based study. Neuroepidemiology 2011; 36:141-147.

79 Sahraian MA, Khorramnia S, Ebrahim MM, Moinfar Z, Lotfi J, Pakdaman H: Multiple sclerosis in Iran: a demographic study of 8,000 patients and changes over time. Eur Neurol 2010;64:331-336.

80 Abedini M, Habibi-Saravi R, Zarvani A Farahmand M: Epidemiology of multiple sclerosis in Mazandran province in 2007 (in Persian). J Mazandaran Univ Med Sci 2008; 18:82-87.

81 Saadatnia $M$, Etemadifar $M$, Maghzi $\mathrm{AH}$ : Multiple sclerosis in Isfahan, Iran. Int Rev Neurobiol 2007;79:357-375.

82 Etemadifar M, Janghorbani M, Shaygannejad V, Ashtari F: Prevalence of multiple sclerosis in Isfahan, Iran. Neuroepidemiology 2006;27: 39-44.

83 Kalanie H, Gharagozli K, Kalanie AR: Multiple sclerosis: report on 200 cases from Iran. Mult Scler 2003;9:36-38.

84 Ebrahimi HA Sedighi B: Prevalence of multiple sclerosis and environmental factors in Kerman province, Iran. Neurology Asia 2013; 18:385-389.

85 Shibasaki H, Kubo N, Nishitani H, Saida T, Ohno Y, Fukuyama Y: Nationwide survey of multiple sclerosis in Japan: reappraisal of clinical features. J Trop Geo Neurol 1992;2:7382.

86 Rosati G: The prevalence of multiple sclerosis in the world: an update. Neurol Sci 2001;22: 117-139.

87 Etemadifar M, Sajjadi S, Nasr Z, Firoozeei TS, Abtahi SH, Akbari M, et al: Epidemiology of multiple sclerosis in Iran: a systematic review. Eur Neurol 2013;70:356-363.

88 Kurtzke J: MS epidemiology world wide. One view of current status. Acta Neurol Scand Suppl 1995;161:23-33.
89 Koch-Henriksen N, Sørensen PS: The changing demographic pattern of multiple sclerosis epidemiology. Lancet Neurol 2010;9:520532.

90 Alshubaili AF, Alramzy K, Ayyad YM, Gerish Y: Epidemiology of multiple sclerosis in Kuwait: new trends in incidence and prevalence. Eur Neurol 2005;53:125-131.

91 El-Salem K, Al-Shimmery E, Horany K, AlRefai A, Al-Hayk K, Khader Y: Multiple sclerosis in Jordan: a clinical and epidemiological study. J Neurol 2006;253:1210-1216.

92 Heydarpour P, Khoshkish S, Abtahi S, Moradi-Lakeh M, Sahraian MA: Multiple sclerosis epidemiology in middle east and north Africa: a systematic review and meta-analysis. Neuroepidemiology 2015;44:232-244.

93 Ladogana A, Puopolo M, Croes EA, Budka H, Jarius C, Collins S, et al: Mortality from Creutzfeldt-Jakob disease and related disorders in Europe, Australia, and Canada. Neurology 2005;64:1586-1591.

94 Noonan CW, Williamson DM, Henry JP, Indian R, Lynch SG, Neuberger JS, et al: The prevalence of multiple sclerosis in 3 US communities. Prev Chronic Dis 2010;7:A12.

95 Niedziela N, Adamczyk-Sowa M, Pierzchala $\mathrm{K}$ : Epidemiology and clinical record of multiple sclerosis in selected countries: a systematic review. Int J Neurosci 2014;124:322-330.

96 Hader WJ, Yee IM: Incidence and prevalence of multiple sclerosis in Saskatoon, Saskatchewan. Neurology 2007;69:1224-1229.

97 Koch-Henriksen N, Sørensen PS: The changing demographic pattern of multiple sclerosis epidemiology Lancet Neurol 2010;9:520-532.

98 Moher D, Liberati A, Tetzlaff J, Altman DG; PRISMA Group: Preferred reporting items for systematic reviews and meta-analyses: the PRISMA statement. Ann Intern Med 2009; 151:264-269. 